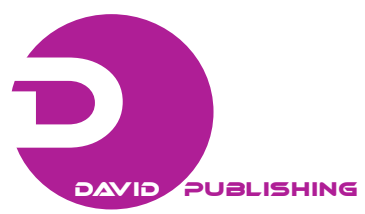

\title{
Tree-Shaped Timber Structural System
}

\author{
Decio Gonçalves ${ }^{1}$, Francisco Antonio Rocco Lahr ${ }^{1}$, Carlito Calil Junior ${ }^{1}$, Mauro Augusto Demarzo ${ }^{2}$ and André \\ Luis Christoforo ${ }^{3}$ \\ 1. Wood and Timber Structures Laboratory, Sao Paulo University, Sao Carlos 13566-590, Brazil \\ 2. Faculty of Civil Engineering, Architecture and Urbanism, Estate University of Campinas-Unicamp, Campinas 13083-900, Brazil \\ 3. Mechanical Department, São João del-Rei Federal University, São João del-Rei 36307-352, Brazil
}

\begin{abstract}
This paper focuses on the main characteristics of a tree-shaped timber structural system or simply tree-shaped. One of them is the complexity of its steel connections, responsible for the joint of bar elements, compounding a complex structural system, which requires the application of the CYPECAD software version 2007 to solve the calculations problems. Its efficiency was confirmed by a variety of laboratory tests carried out with the whole structure. The tree-shaped is a timber structure that can be used in a large number of destinations, including residences, malls, sheds, hangars, etc.. Originally, it was conceived based on the well-known masterpiece "Sagrada Família", whose author was Architect Antoni Gaudi I Cornet (1852-1926) in Barcelona/Spain. It was designed at the end of 19th century and its construction is still not finished. Gaudi inverted the logical order of the gothic concepts, i.e., light weights below and heavy weights above. Based on this concept, he always had in mind the figure of a tree in nature. The tree-shaped follows the same idea, using timber pieces connected by steel plates. Theoretical and numerical analyses have shown its efficiency and lightness for use in timber structures.
\end{abstract}

Key words: Tree-shaped, timber structure system, constructive rationality, modulated system, timber dowels, wood.

\section{Introduction}

The tree-shaped timber structural system, or simply tree-shaped, was conceived according to an architecture that privileged serious concerns about nature and its preservation, causing minimal environmental impacts on the surroundings. This approach resulted in few support points on the soil and in a modular fabricated system full of constructive rationality and elements made of wood, a renewable material comfortable to human touch. When all these attributes are put together, it becomes a singular and outstanding structural system. It also demands less energy for its production and erection when compared with other materials that is why legal and certificated wood would be a natural choice. If all these hypotheses and conditions are considered, the ideal structural system will resemble a metaphorical image

Corresponding author: Decio Gonçalves, professor, research fields: architecture and timber structural engineering. E-mail: dg@sc.usp.br. of a tree, such as the pillars (Fig. 1) of the "Sagrada Família" work building [1]. Another design peculiarity is the bio climatically aspects involved in this structural system, providing natural ventilation and chimney effect due to special characteristics related to the emptiness of the superior part of the structural system. It is formed by FS (floor slabs), supported by three DC (diamond columns). These columns are compounded by six faces LIB (lower inclined bars) and six UIB (upper inclined bars) placed above them, resulting in three levels (Fig. 2).

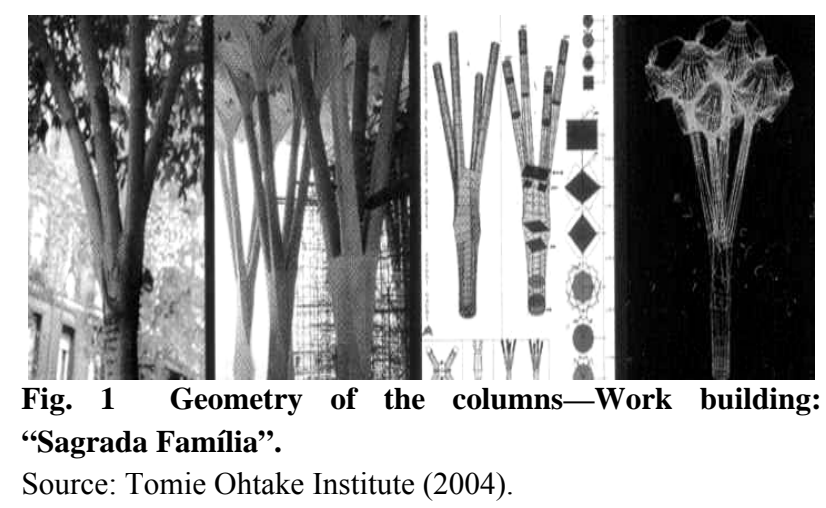




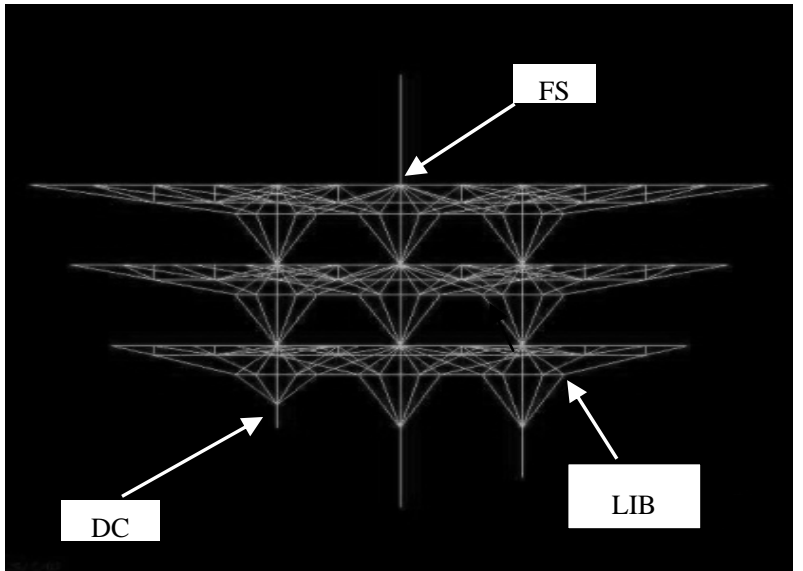

Fig. 2 First numerical model of tree-shaped.

Source: Civil Engineer Marcos Monteiro [2].

This system is provided with steel connections able to establish continuity to the members as well as strenght and stability to the system. Unlike the rigid nodes of a tree, the tree-shaped has articulated nodes because of its trussed spatial beams (Fig. 2).

One of the most important caracteristics of the system is the SC (steel connections), connecting timber bar elements in the whole structural system, including “diamond"-shaped columns, ST (spatial trusses) and FS (floor slab) (Fig. 3).

All bar elements are fixed with timber dowels of Peltogyne recifencis Ducke (hard specie), strength C60 Class, with 16 mm diameter (Figs. 4 and 5).

Using this technology, it is possible to obtain some benefits such as the reduced number of pillars on the ground due to the more favourable load transfer mechanism. Also, the structural weight is substantialy lighter than other conventional timber structural systems, requiring simpler foundations.

The tree-shaped is an innovative technology that requires small construction site areas because the structural modules can be stored in pallets, utilizing reduced space in load trucks.

The design of the the tree-shaped is singular due to these specific supports and particular nodes. It also enables structural implementation in different soils with variable topographies, because its concrete pillars adapt to several heights related to the variety of declivities.
The system can also be reused in other locations because of its assembly process, i.e., the SC (steel connections) are fixed with fasteners (timber dowels) that allow for easy dismantlement.

Danatzko and Sezen [3] pointed out that "the concept behind the maximization of structural reuse is to generate layouts and designs that produce the least amount (quantity) of solid waste at end-of-life or permit for the greatest amount of whole or partial system utilization and/or structural component reuse".

Besides, all the described characteristics make it a singular structural system, according to Dias [4]:

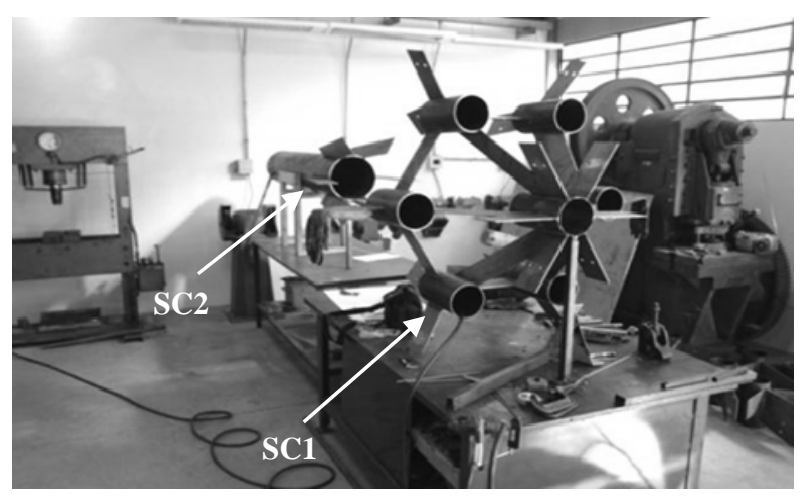

Fig. 3 Steel connections: SC1 and SC2.

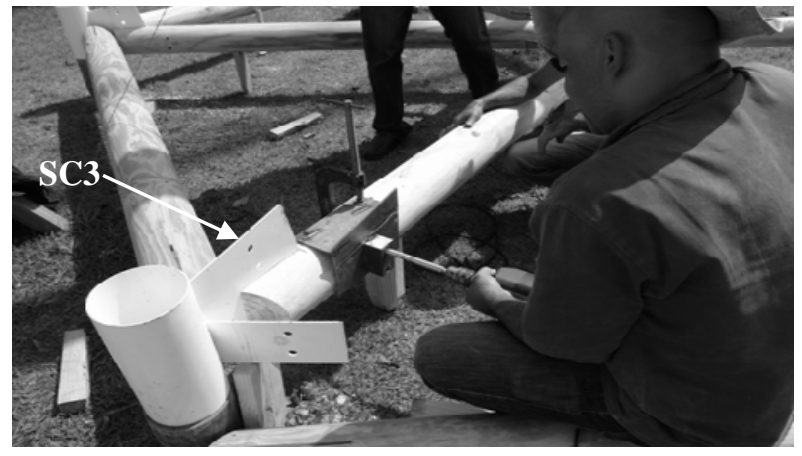

Fig. 4 Steel connections: SC3.

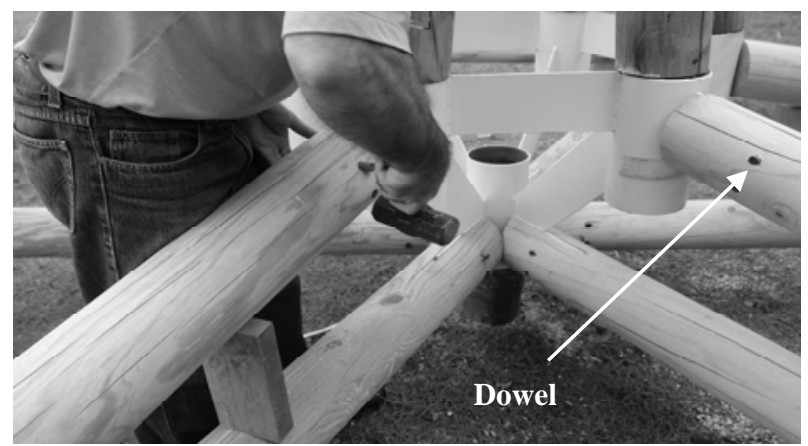

Fig. 5 Fixing timber dowels. 
"tree-shaped has a great potential for generating natural resources in the carbon marked (one carbon credit is equal to one equivalent $\mathrm{CO}_{2}$, which means, for instance, to drive a car for 2,084 $\mathrm{km}$ ) and being registered as a clean technology in the United Nations". This fact reinforces the utilization of timber in a constructive manner and is an effective guarantee of carbon sequestration.

The aim of this paper is to describe the general specifications and special and unique characteristics of the Tree-Shaped Timber Structural System, which can afford to several architectonic applications.

\section{Wood}

Wood is a renewable material that requires very little energy for processing. Furthermore, wood is pleasant to the touch and has many attributes, especially with regard to its structural characteristics. When treated with the appropriate chemical substances, wooden material remains durable for a long time. Contrary to what people think, wood is generally resistant to fire, especially when considering solid elements thicker than one inch. In this situation, fire spreads out and destroys the superficial layer very rapidly, but then the charring slows down due to the insulation properties of the char layer which protects the wood.

Concerned with the resistance under fire conditions, Moura [5] states that "with or without protection against fire, solid wood members have a great probability of resisting loads at high temperatures, before collapsing".

Sawn and round timber comprises a great variety and a large quantity of exploitable Brazilian species. In accordance with Cesar [6], this new technology has been influencing a significant range of other Brazilian firms in the field of timber structures.

\section{Tree-Shaped Configurations}

The tree-shaped allows a great variety of structural configurations to be implemented, which can be used for different destinations, including single and multi-storey residences, research centers, malls, hangars, among others.

Several structural types can be chosen, according to the number(s) of support points on the ground, which can vary from one to three.

\subsection{One Support on the Ground}

\subsubsection{Module}

The module (Fig. 6) is a structural system with only one support point in the ground, consisting of primary, secondary and beam bars, which together form a roof-FS (floor slabs) composed of a modulation of equilateral triangles - the BGM (basic geometric module) in the system-resulting in a hexagonal surface. This hexagon is supported by sloping top bars distributed over a support hexagon, in six bars, forming a "diamond" column. It has one DC and three $\mathrm{ST}$, having a $20 \mathrm{~m}^{2}$ of building area.

\subsubsection{Module Prototype}

Thinking in social applications, this structural type can be used as a short community centre, a pavilion for lectures for children or a place for recreation activities.

This architectonic artifact can be constructed on any University Campus, even in poor communities, where there is a lack of social equipment.

The module prototype was assembled and installed in the Wood and Timber Structures Laboratory of the

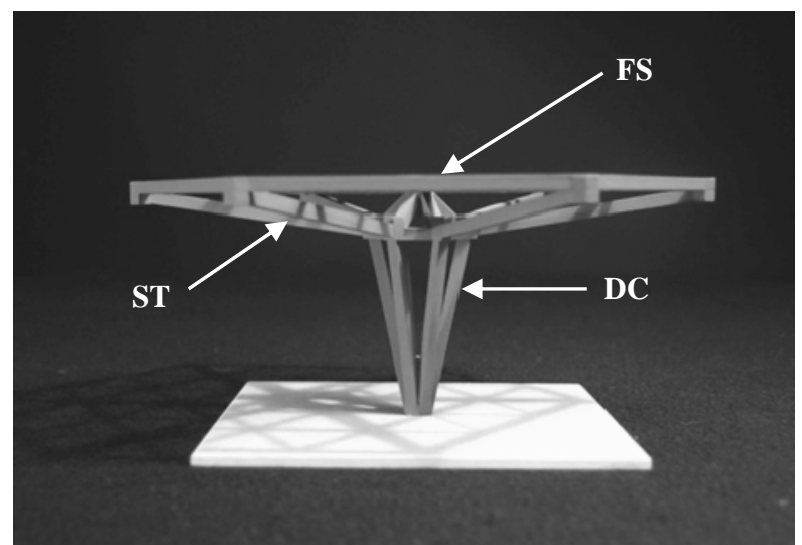

Fig. 6 Module model in 1:25 scale (ST spatial truss, DC diamond column and FS floor slab). 


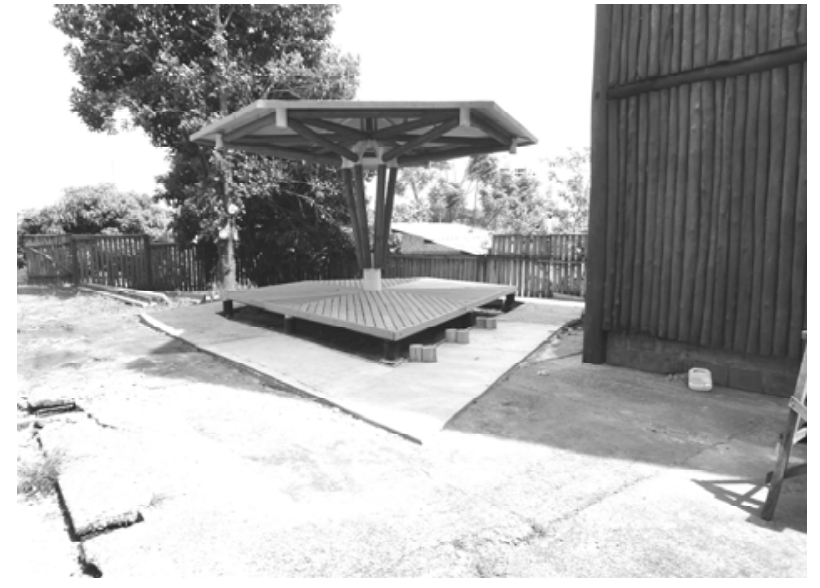

Fig. 7 Module prototype.

Department of Structural Engineering site, LaMEM/SET/EESC/USP (Fig. 7).

3.1.3 Tree-Shaped Timber Stayed Structural System-S2ETA: Named Stayed System

The stayed system is other approach in the conceptual design of the tree shaped with specific architectonic characteristics.

The stayed system can be used in single and multi-storey family housing. In this example, it is a two-storey residence with $85 \mathrm{~m}^{2}$ of building area (Figs. 8 and 9).

\subsection{Three Supports on the Ground}

\subsubsection{Tree-Shaped Timer Structural} System-SETA

The tree-shaped design was the first approach in relation to the metaphorical image of the tree. It was created by Architect Antoni Gaudi and developed in Brazil by Architect Marcos Acayaba and his partner Civil Engineer Hélio Olga Junior, responsible for the structural system calculation.

This system creates a DC and ST, which allows for long-span floor slabs.

It intends to be completely in accordance with the organic principles applied by master Architect Frank Lloyd Wright in his Usonian House works in the United States, in the late 1920s.

Below, it is shown an example of a residence with $385 \mathrm{~m}^{2}$ of building area (Fig. 10).

\section{DC (“Diamond" Column)}

DC has unique characteristics of designed and constructive concepts. Visually, it looks like a harmonious

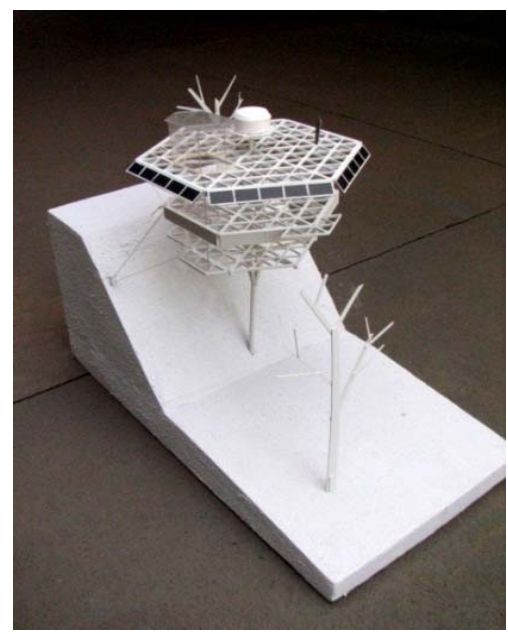

Fig. 8 S2ETA, side view.

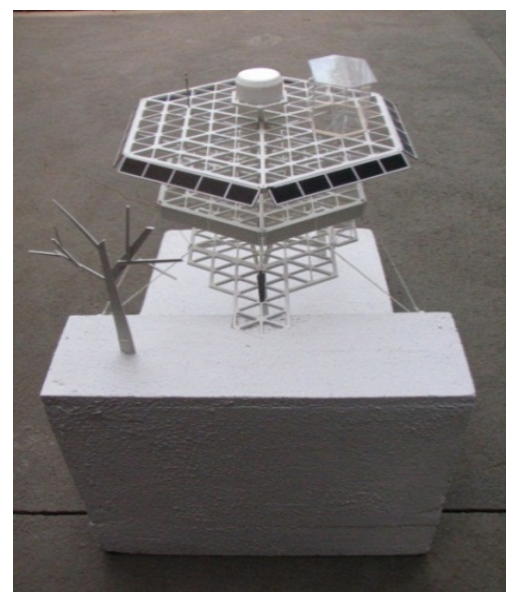

Fig. 9 S2ETA rear view.

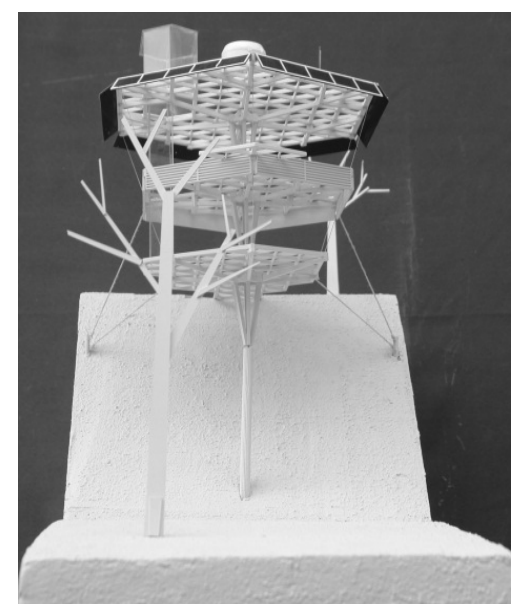

Fig. 10 S2ETA, frontal view. 


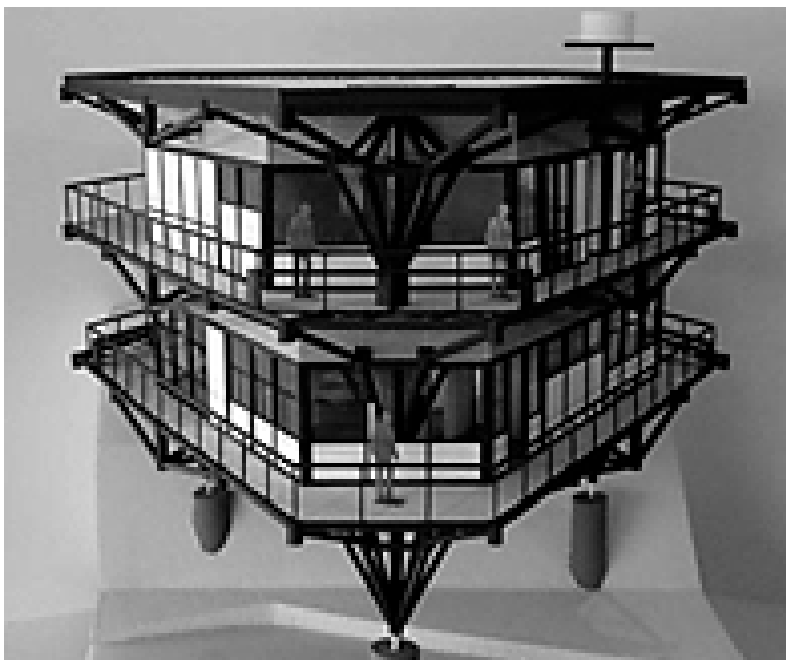

Fig. 11 Tree-shaped timber modular structural system, model in 1:50 scale of a two-storey single family with 385 $\mathbf{m}^{2}$ of building area.

tree-shape metaphoric image, with plenty of plastic beauty. At the same time, from its constructive elegance and visual lightness, the structure transfers the loads through its elements in an effective way, reducing the stresses in the elements.

Because of its constructive simplicity, only one chief-carpenter and one carpenter are needed for the erection. As the structure is light weight, there is no need for large equipment during the assembling of the system on the building site.

There is minimal environment impact on the tree-shaped implementation, because the architectonic artifact has only three support pillars in contact to the ground. This system presents an excellent cost-benefit ratio, and can be used for different destinations, including malls, plane hangars, research centers, among others.

The system allows for easy industrialized processes. All components are packet and moved to the building site and easily assembled.

\section{Calculation and Modelling}

CYPECAD software, version 2007 (computer program developed by CYPE INGENIEROS SA based on the CAD software) was used to calculate the bar forces (the modelling and the discretization of the tree-shaped are showed in Figs. 12 and 13). It is implemented in a FE (finite element) software package, which considers ABNT NBR 7190:1997 Brazilian Code [7] requirements. Three dimensional elements to represent timber members were considered in the discretization of the structure. There are two nodes in each bar element and three degrees of freedom per node, i.e., these elements do not allow relative translations along axes $x, y$ and $z$, with free relative rotations allowed around the same ones.

The bar elements resist tension and compression, considering that all joints are pinned except the base joints. This numerical simulation allows a detailed analysis of the aspects of interest such as the evaluation of the most stressed members and the stress concentration in the connections, which can not be detected in lab tests.

A numerical simulation was performed to calculate the stress distribution in the elements and construct a module named prototype.

Fig. 14 illustrates the four $\mathrm{SC}$ (steel connection) groups labelled $\mathrm{SC} 1, \mathrm{SC} 2, \mathrm{SC} 3$ and $\mathrm{SC} 4$.

Bar cross-section dimensions are shown in Fig. 15.

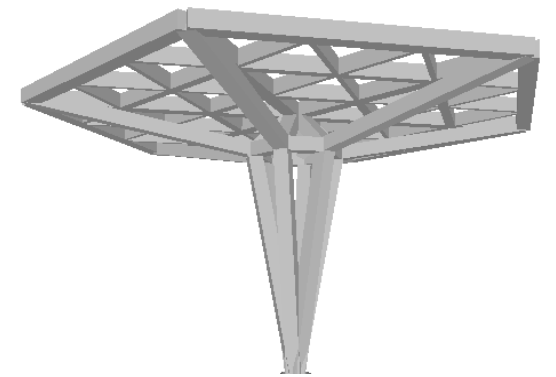

Fig. 12 Modelling of the tree-shaped module in CYPECAD: real profile.

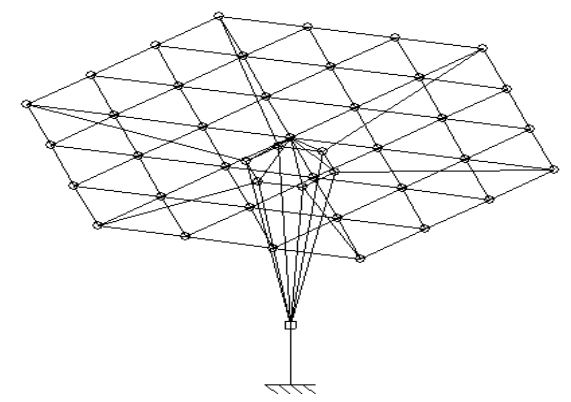

Fig. 13 Modelling of the tree-shaped module in CYPECAD: discretization of bar elements and joints. 


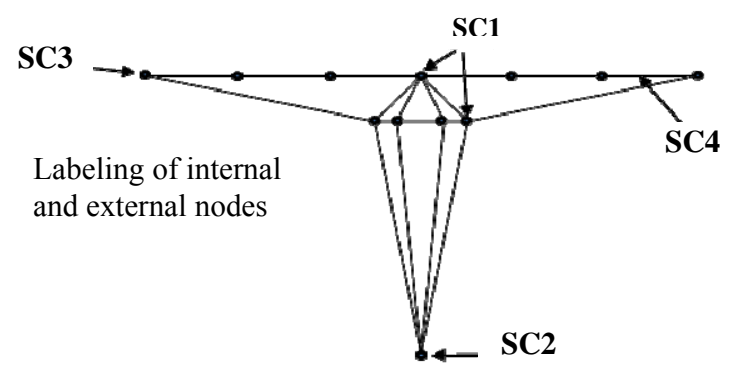

Fig. 14 Schematic module profile-four SC groups.

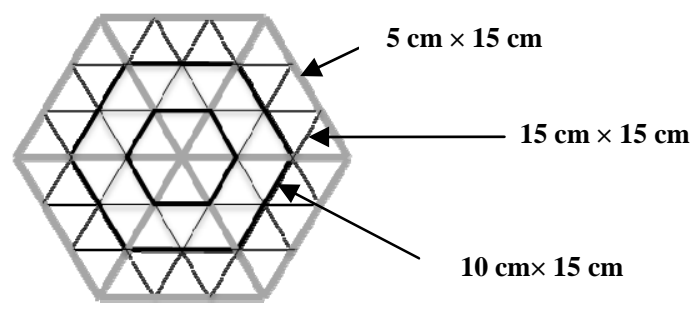

Fig. 15 Bar cross-section dimensions of the Module in plan view.
Table 1 (plates) and Table 2 (tubes) show the dimensions of four SC groups, where: ${ }^{1} b=$ breadth, ${ }^{2} h$ $=$ height, ${ }^{1} \mathrm{~d}=$ diameter and ${ }^{2} \mathrm{~L}=$ length.

\section{Analysis and Results}

The following load values were adopted:

(1) Permanent actions:

Timber: $7 \mathrm{kN} / \mathrm{m}^{3}$; steel: $78 \mathrm{kN} / \mathrm{m}^{3}$;

(2) Variable action-Wind:

Maximum action: $10.29 \mathrm{kN}$.

Wind load: magnitude of forces due to wind load was determined based on Brazilian NBR 6123:1988 requirements.

Note: None imposed load was considered in this system.

Table 1 Characteristics of the steel plate connections of the module.

\begin{tabular}{lclllr}
\hline Steel connection & No. of steel plates & ${ }^{1} \mathrm{~b}(\mathrm{~mm})$ & ${ }^{2} \mathrm{~h}(\mathrm{~mm})$ & Thickness $(\mathrm{mm})$ & Weight $(\mathrm{daN})$ \\
\hline$(\mathrm{SC} 1)$ & 6 & 250 & 130 & 4.18 & 6.55 \\
& 12 & 300 & 130 & 4.18 & 15.90 \\
& 6 & 350 & 130 & 4.18 & 9.16 \\
& 6 & 450 & 130 & 4.18 & 11.78 \\
\hline (SC2) & 6 & 250 & 130 & 4.18 & 6.55 \\
& 6 & 450 & 130 & 4.18 & 11.78 \\
\hline (SC3) & 18 & 250 & 130 & 4.18 & 79.64 \\
& 6 & 300 & 130 & 4.18 & 144.00 \\
\hline (SC4) & 132 & 250 & 130 & 4.18 & 233.21 \\
\hline Total sheet weight & & & & \\
\hline
\end{tabular}

Table 2 Characteristics of the steel tube connections of the module.

\begin{tabular}{lllcllr}
\hline Steel connection & No. of tubes & ${ }^{1} \mathrm{~d}(\mathrm{~mm})$ & ${ }^{2} \mathrm{~L}(\mathrm{~mm})$ & Thickness $(\mathrm{mm})$ & Weight density $\left(\mathrm{daN} / \mathrm{m}^{3}\right)$ & Weight $(\mathrm{daN})$ \\
\hline (SC1) & 7 & 152.4 & 300 & 3.0 & 11.050 & 23.11 \\
$(\mathrm{SC} 2)$ & 1 & 323.0 & 2,000 & 6.4 & 49.797 & 100.00 \\
(SC3) & 6 & 152.4 & 300 & 3.8 & 11.050 & 19.89 \\
\hline Total sheet weight & & & & 143.10 \\
\hline
\end{tabular}

Table 3 Wind parameters and wind force.

\begin{tabular}{|c|c|c|c|c|c|c|c|c|c|}
\hline \multirow{2}{*}{ Wall } & \multicolumn{2}{|c|}{$\overline{C_{e} \alpha}$} & \multirow{2}{*}{$-\mathrm{Q}\left(\mathrm{kN} / \mathrm{m}^{2}\right)$} & \multirow{2}{*}{$\mathrm{A}\left(\mathrm{m}^{2}\right)$} & \multicolumn{2}{|c|}{$\mathrm{C}_{\mathrm{e}}-\mathrm{C}_{\mathrm{i}}{ }^{1} \mathrm{Cpi}$} & \multirow{2}{*}{$\begin{array}{l}\mathrm{qA} \\
(\mathrm{kN})\end{array}$} & \multicolumn{2}{|c|}{$\mathrm{F}(\mathrm{kN}){ }^{1} \mathrm{Cpi}$} \\
\hline & 0 & 90 & & & -0.3 & 0 & & -0.3 & 0 \\
\hline $\mathrm{A} 1$ and $\mathrm{A} 2$ & -0.8 & & 0.0079 & 12.96 & & -0.8 & 10.29 & & -8.23 \\
\hline $\mathrm{A} 2$ and $\mathrm{B} 2$ & -0.5 & & 0.0079 & 12.96 & & -0.5 & 10.29 & & -5.15 \\
\hline $\mathrm{C}$ & -0.7 & & 0.0079 & 12.96 & & 0.7 & 10.29 & & 7.20 \\
\hline D & -0.4 & & 0.0079 & 12.96 & & -0.4 & 10.29 & & -4.12 \\
\hline A & & 0.7 & 0.0079 & 12.96 & 1.0 & & 10.29 & 10.29 & \\
\hline B & & -0.4 & 0.0079 & 12.96 & -0.1 & & 10.29 & -1.03 & \\
\hline $\mathrm{C} 1$ and $\mathrm{C} 2$ & & -0.8 & 0.0079 & 12.96 & -0.5 & & 10.29 & -5.15 & \\
\hline $\mathrm{C} 2$ and D2 & & -0.4 & 0.0079 & 12.96 & -0.1 & & 10.29 & -1.03 & \\
\hline
\end{tabular}

${ }^{\mathrm{T}} \mathrm{Cpi}=$ Pressure internal coefficient 
The characteristic velocity $V_{k}$ and wind dynamic pressure $q$ are expressed by Eqs. (1) and (2), respectively, in accordance with ABNT NBR 6123:1998 Brazilian Code [8]:

$$
\begin{aligned}
V_{k} & =V_{0} S_{1} S_{2} S_{3} \\
q & =0.613 V_{k}{ }^{2}
\end{aligned}
$$

where, $V_{0}=40 \mathrm{~m} / \mathrm{s}$ is the basic wind speed in the region (São Carlos, SP, Brazil), $S_{1}=1.0$ at the ground level, $S_{2}$ depends upon the terrain and height dimension (h) of the architectural artefact to the ground, and $S_{3}$ is the factor based on statistical concepts considering the degree of reliability required and the building lifecycle $\left(S_{3}=1.0\right.$, Group 2).

$S_{2}$ was defined as being in Category II, with a size of Class $\mathrm{A}$, and is given by:

$$
S_{2}=b F_{r}\left(\frac{z}{10}\right)^{p}
$$

where, $F_{r}=$ blast factor (in this case 1.0); $b=$ smaller side of the structure $(b=1.0) ; p=$ exponent of the exponential variation law of $S_{2}=0.085 ; z=$ elevation above the ground $=2.925 \mathrm{~m}$.

The following results were obtained:

$$
\begin{gathered}
S_{2}=0.90 \\
V_{k}=36 \quad \mathrm{kN} / \mathrm{m}^{2} \\
q=0.794 \quad \mathrm{kN} / \mathrm{m}^{2}
\end{gathered}
$$

To determine the wind force on the building wall with an area $A$ (area on which the wind pressure is applied: $A=12.96 \mathrm{~m}^{2}$ ), the $h / b$ ratio must be computed:

$$
\frac{h}{b}=\frac{2.40}{5.40}=0.44 \leq 0.5
$$

Figs. 15 and 16 show the pressure coefficient and shape coefficient, outside of the side walls and front walls (wind at $0^{\circ}$ and at $90^{\circ}$ ).

The wind force $F$ was calculated by:

$$
F=\left(C_{e}-C_{i}\right) q A
$$

where $C_{e}=$ outer pressure coefficient and $C_{i}=$ internal pressure coefficient.

The wind parameters and results are shown in Table 3.

Fig. 17 shows live dead load in nodes, Figs. 18 and
19 show live loads (wind acting as NBR 6123:1988 requirements respectively) and Fig. 20 shows the most stressed bar in the module, signed by "BZINF". Bar solicitations were determined using CYPECAD, as pointed out in anterior item.

Eaves were employed in all roof perimeters. This option allows to consider equivalent magnitude, even with little difference that can be observed in the node influence areas.

The structural forces in the timber elements of the module were calculated by CYPECAD software. The module design was introduced in this software and the floor plans and views were imported from AUTOCAD 2006.

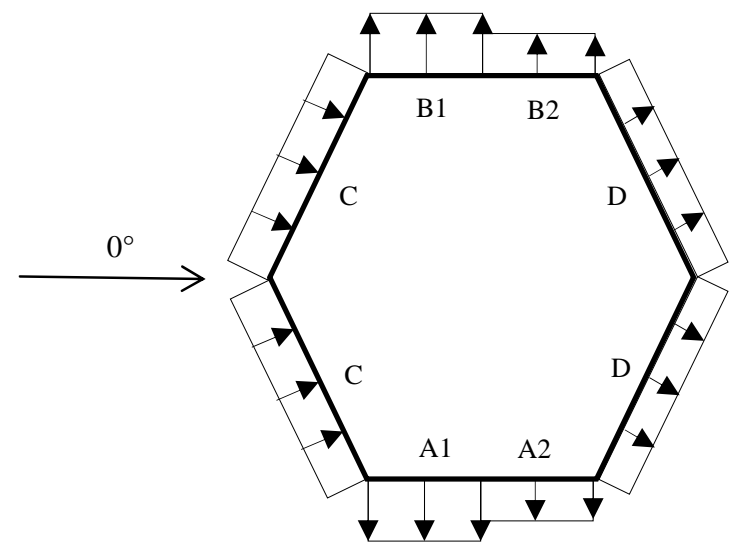

Fig. 15 Wind at $0^{\circ}$ : pressure coefficient and shape coefficient external to the side walls and front walls.
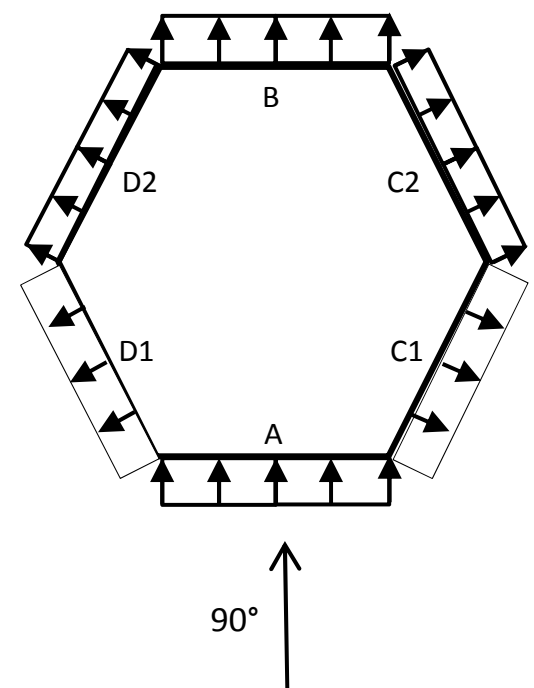

Fig. 16 Wind at $90^{\circ}$ : pressure coefficient and shape coefficient external to the side walls and front walls. 


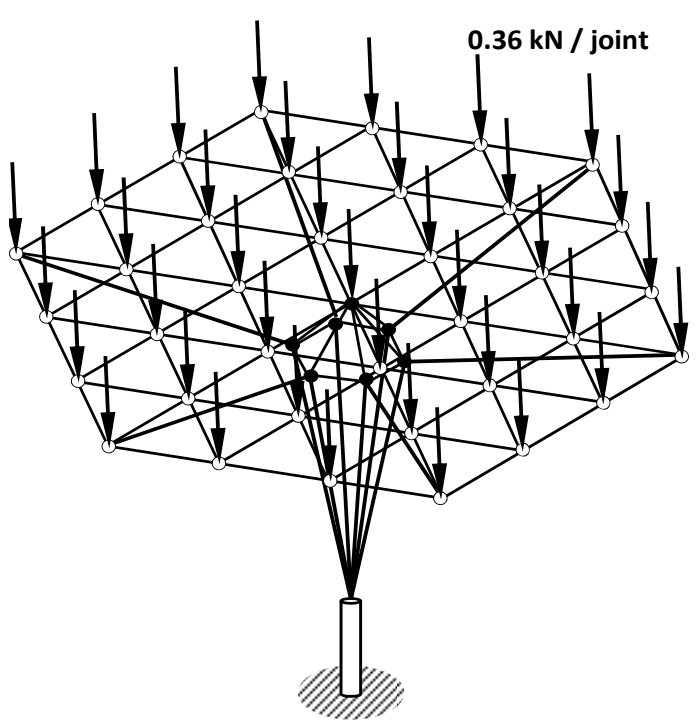

Fig. 17 Permanent actions (dead weight).

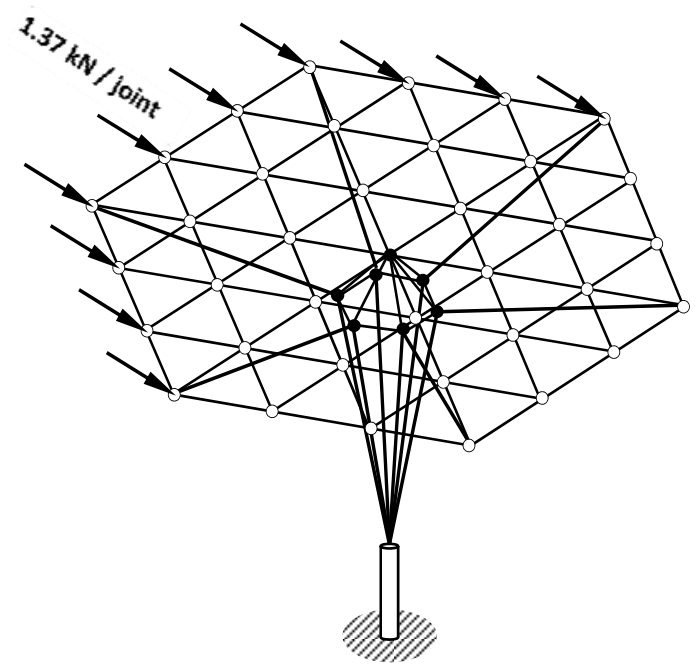

Fig. 18 Accidental live loads (wind at $90^{\circ}$ ).

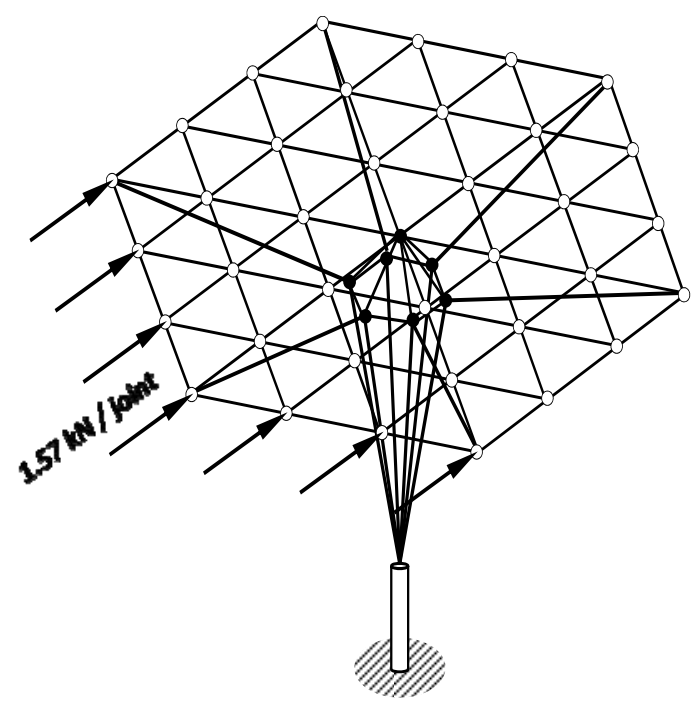

Fig. 19 Accidental live loads (wind at $0^{\circ}$ ).

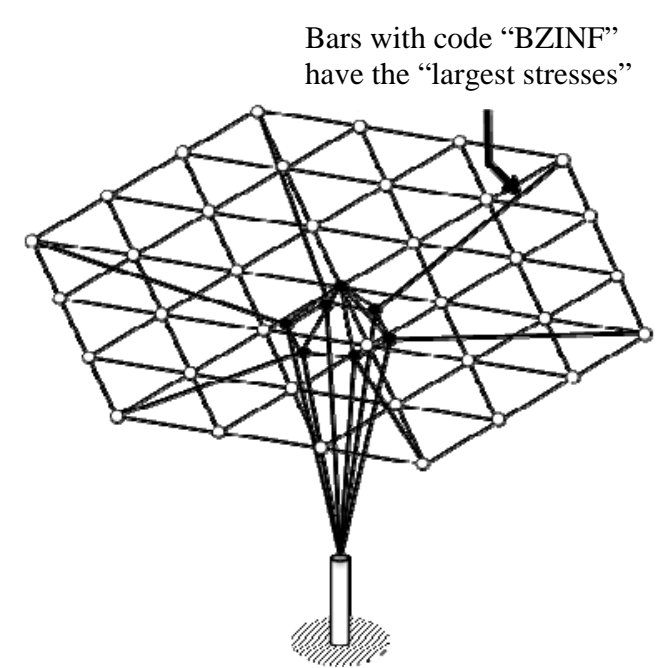

Fig. 20 System bars with largest stresses in the module: code BZINF bars.

The prototype module presented the following characteristics:

(1) Support elements (column): $16 \mathrm{~cm}$ medium diameter cylindrical bars, according to Brazilian ABNT NBR 7190:1997 code;

(2) Steel connections: Stainless steel of $4.18 \mathrm{~mm}$ thick plates and $15 \mathrm{~cm}$ diameter tubes. The welded plates were designed with two holes to allow for the insertion of wooden dowels to connect the “diamond”-shaped elements;

(3) Dowel connectors: $16 \mathrm{~mm}$ diameter dowels made from Peltogyne recifencis Ducke species (hardwood specie), C60 strength Classes, related to Brazilian NBR 7109:1997 code, Roxinho in the local commercial language.

The SC of the "diamond"-shaped column was constructed in the mechanical work lab (Fig. 3) at the São Carlos Engineering School, São Paulo University (EESC/USP).

This test was conducted with the DC in a horizontal position to facilitate the application of compression forces to these structural elements (Fig. 21).

Testing compression load on "diamond" was applied using one steel cable (1), as showed in Fig. 21. This element once tensioned, causes compression parallel to the grain in six rounds bars (2), transmitted 


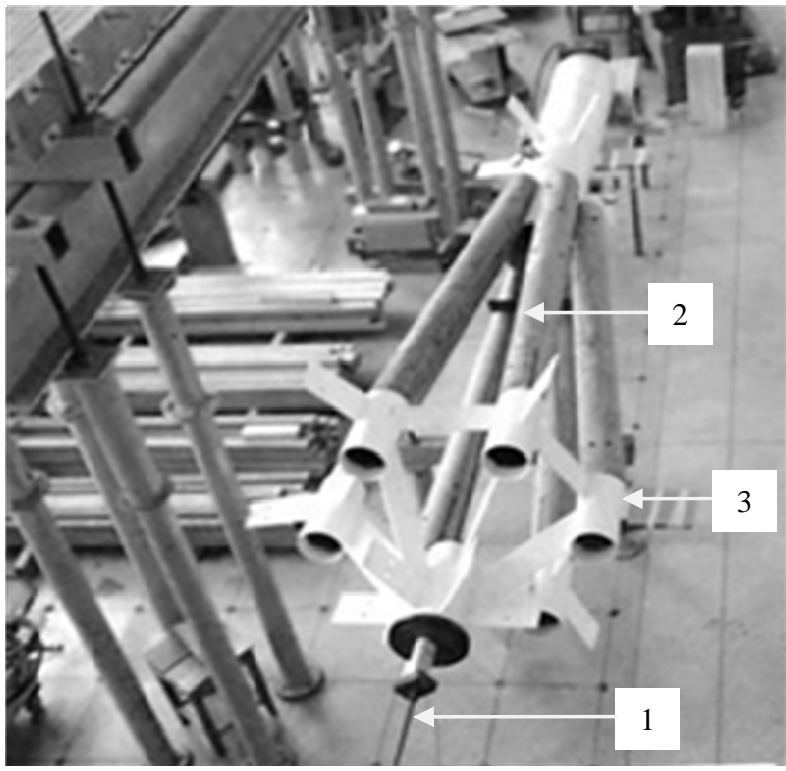

Fig. 21 Top view of compression tests on the "diamond" column through the KIOWA device in LaMEM/SET/EESC/USP.

by steel connections (3) that embrace them in their endings. Strain gauges were fastened and monitored by Kyowa equipment to control the load applied.

The relative displacements between the steel components of the structural system were measured, and very small values $(0.03 \mathrm{~mm}$ was the maximum measured displacement) were obtained.

The force applied in steel cable (about $90 \mathrm{kN}$ ) imposes in each one of six round bars a force around $15 \mathrm{kN}$. This value is more than twice the maximum force expected by static evaSluations $(7.3 \mathrm{kN})$ in the mentioned members.

\section{Conclusions}

The tree-shaped is a timber structural system that can be used for a number of different applications. The specific and unique characteristics allow its implementation in different declivities of the soil and its cost-effective budget is considerable favorable for investments in building construction, particularly in housing. It causes a minimal impact on the environment and needs a small space for the working areas, requiring only two or three professionals to assemble the structure.

\section{Acknowledgments}

The authors would like to acknowledge CNPQ (Federal Agency of Scientific and Technological Improvements, Brazil) for the financial support provided to this research and São Carlos Engineering School at Sao Paulo University—EESC/USP.

\section{References}

[1] Gaudi: The Search of Form, Tomie Ohtake Institute, São Paulo, Brazil, 2004. (in Portuguese)

[2] M. Marcos, Calculation of SETA, Terms of Initial Structural Analysis, Sao Paulo, Brazil, 2005.

[3] J.M. Danatzko, H. Sezen, Sustainable structural design methodologies, Journal of Engineering Structures 16 (4) (2011) 186-190.

[4] S. Dias, Technology that links chance of profit and social-environment preoccupation, CONECTA Journal_PIT/SP 2 (2008) 34-35. (in Portuguese)

[5] E.P. Moura, Study of rate carbonization and its relation with the resistance of structural components, in: 9th Brazilian Meeting in Wooden and Timber Structures, Brazil, July 2004. (in Portuguese)

[6] S.F. Cesar, Timber hauff structures in Brazil, Technical Dissertation, Sao Carlos Engineering School, Sao Paulo University, Sao Paulo, Brazil, 1991, p. 185. (in Portuguese)

[7] ABNT, NBR 7190:1997, Timber Structural Design, ABNT (Brazilian Association of Technical Codes), 1997. (in Portuguese)

[8] ABNT, NBR 6123:1998, Loads Due to the Wind on Buildings, ABNT (Brazilian Association of Technical Codes), 1998. (in Portuguese) 